\title{
Türkülerde ‘Evlilik Geçiş Dönemi’ Metaforu Olarak 'Köprü'
}

\section{The 'Bridge' as a Metaphor for The 'Marriage Transition Period' in Turkish Folk Songs}

\section{Betül Görkem ${ }^{1}$ (D)}

'Dr. Öğr. Üyesi, Erciyes Üniversitesi, Edebiyat Fakültesi Türk Halk Bilimi Bölümü, Kayseri, Türkiye

ORCID: B.G. 0000-0003-0838-5761

Sorumlu yazar/Corresponding author: Betül Görkem,

Erciyes Üniversitesi, Edebiyat Fakültesi Türk Halk Bilimi Bölümü, Kayseri, Türkiye

E-mail: betulaydogdu@gmail.com

Başvuru/Submitted: 08.09.2021

Revizyon Talebi/Revision Requested: 09.11.202 Son Revizyon/Last Revision Received: 13.11.2021 Kabul/Accepted: 23.11.2021

Online Yayın/Published Online: 10.12.2021

\section{Atıf/Citation:}

Gorkem, B. (2021). Türkülerde 'evlilik geçiş dönemi' metaforu olarak 'köprü'. TUDED, 61(2), 631-646

https://doi.org/10.26650/TUDED2021-993029

\section{ÖZET}

Geçiş dönemleri, insan hayatındaki önemli kırılma noktalarına işaret eder. $\mathrm{Bu}$ kırılma noktaları hayatımızın yeni bir döneme geçtiğini göstermesi açısından 'geçiş dönemi' olarak adlandırılır. Doğum, evlenme ve ölüm hayatımızdaki başlıca geçiş dönemleridir. Türk kültüründe evlenme geçiş dönemi kız isteme ile başlar. Bu süreç, sözlenme (söz kesme), nişanlanma ve düğün aşamalarıyla devam eder ve düğ̈̈n sonrasına yapılan ziyaretler ile tamamlanır. Türk dili ve edebiyatı alanında 'metafor' kavramı önceleri mecaz ve istiare kavramlarıyla karşılanmıştır. Lakoff ve Johnson ise 'metafor'u bir şeyin başka bir șey vasıtasıyla anlaşılması olarak açıklar. Bir kavram, benzetme, karşılaştırma gibi zihnî süreçler doğrultusunda başka bir anlamı yüklenebilir veya başka bir anlama işaret edebilir. Bu yeniden anlamlandırmada geleneksel ve kültürel unsurlar etkili olabileceği gibi, kişinin/ sanatçının bireysel buluşları da etkili olabilir. Çalışmada bir metafor olarak 'köprü' kelimesinin, türkülerde 'evlilik geçiş dönemi'ne işaret etmesi değerlendirilmiştir. Köprünün iki yakayı birbirine bağlaması, sağlamlığı, geçiş süreci gibi hususiyetlerin evlilik geçiş dönemi ve köprü kavramları arasındaki haritalamada kullanıldığ görülmektedir. Metaforların anlamlandırılmasında bağlam oldukça önemlidir. Örnek olarak verilen bazı türkülerin kına gecelerinde söylendiği görülmektedir ve türkülerde geçen 'köprü' kelimesinin metaforik anlamının yorumlanmasında önemli bir yere sahiptir.

Anahtar Kelimeler: Sözlü kültür, türkü, metafor, evlilik geçiş dönemi, 'köprü’

\section{ABSTRACT}

Transition periods mark important milestones in a person's life. They show us that our lives are evolving into a new period. Birth, marriage, and death are the most important of these. Marriage in Turkish culture begins with the groom's family asking the bride's family to give their daughter's hand. Next, comes the engagement and then the wedding and finally post-wedding visits. In the field of Turkish language and literature, the concept of 'metaphor' was initially met with the concepts of mecaz and istiare. Lakoff and Johnson, however, describe 'metaphor' as the understanding of one thing through another. A concept can either take on or allude to another meaning in line with analogy or comparison. While traditional and cultural elements can prove effective in serving that exact purpose, so can the individual inventions of people/ artists. This study focuses on the word 'bridge' in Turkish folk songs as a metaphor referring to marriage. The bridge not only connects the two sides and embodies strength, but also the crossing of a bridge symbolizes marriage as a transition period. 
Context is very important in interpreting metaphors. It is seen that some of the folk songs given as examples in this study are sung during henna nights. These folk song samples have an important place in the interpretation of the metaphorical meaning of the word 'bridge'.

Keywords: Oral culture, Turkish folk songs, metaphor, marriage transition period, 'bridge'

\section{EXTENDED ABSTRACT}

There are three important transitional periods that shape human life. The first transition period is birth. This transition period starts before a person's birth. The second important transition period is marriage. Marriage is a transitional period that a person consciously participates in. The third important transition period is death. Death transition period rituals start before the death of a person and end after the death.

Marriage is a remarkable transition period in terms of conscious participation and the vitality of the individual throughout the process. Marriage has a very important place in societies in terms of the formation of the family institution. It is the whole process of a person leaving the family they were born into and establishing a new home and forming their own family. When marriage rituals end, the person starts a new life. In addition to this, their social status also changes from "single" to "married." This transition period is a multi-stage and long process when we look at social practices. In this process, the person is slowly getting ready for married life and trying to get used to their new life so that they can lead a balanced and peaceful life in their new home. The person is at a 'threshold' when the marriage transition period practices begin, after the marriage process is completed, the threshold has been crossed and the new life has fully started.

The term metaphor is seen as equivalent to the terms mecaz and istiare in Turkish. Following the studies of Lakoff and Johnson, the concept of metaphor was reinterpreted and the term "conceptual metaphor" began to be preferred.

Metaphors are created by establishing connections between two different elements. Comparing elements and/or establishing similarities between elements are ways of creating metaphors.

Although the formation, establishment, and use of metaphors in our minds may seem like an individual action or thought, some metaphors are understood and used in the same way throughout the society; therefore, it is seen that the metaphor is related to the culture of the society. Metaphors are shaped by the influence of the collective consciousness and subconscious and by the culture of the society. They are transferred to the new generation through traditions. The most important part in this transfer is language. As metaphors are transferred by language, they carry the culture, attitudes, and thoughts of the society, however personal they may seem to be. Since language is the most important carrier of culture, we can argue that cultural 
differences can be observed better in linguistic material.

Kayhan Şahan says that we can divide the metaphors in literary works into two groups: a) Traditional-cultural metaphors, and b) New (original) metaphors.

Oral literature products can be understood by the people without the need for explanation, as they are produced within the tradition and carry the traces/connections of the collective unconscious.

When using metaphors, the same word can be used to denote different meanings. To understand which concepts or images these different meanings are related to, the context must also be known.

We can think that in many products of Turkish Oral Literature, there are metaphorical meanings according to the referents of the concepts used, apart from the meaning stated. In this study, the meaning connections of the "bridge" metaphor in folk songs will be explained with examples.

Folk songs, one of the most common types of Turkish Anonymous Oral Literature, contain many metaphors that reflect the subconscious of the society. While some of these metaphors have mythological origins, some of them carry clues about societal institutions and the life of a person.

The "bridge" in folk songs does not always simply refer to a structure. In some folk songs, it can be thought that the bridge refers to the marriage process, which is one of the important transition periods in human life. Just as a bridge connects two sides, marriage is a transition period between being single and being married. While one of the legs of the bridge is in the period of celibacy, the other leg is in the period of marriage. The transition period between these two periods is symbolized by the bridge.

In this study, it is seen that the word "bridge" in some folk songs sung especially on henna nights, refers to the "marriage transition period." As noted above, the context of the folk song has been effective in the interpretation of this layer of meaning. 
İnsan, dünyaya geldiği andan itibaren içinde yaşadığı toplumun kültürüyle kültürlenir. Kültürlenme faaliyeti bireyin henüz bilinçli olmadığı bebekliğinden başlar ve bireyin ölümüne kadar sürer. Bu süreç içinde insanın hayatını şekillendiren üç önemli geçiş dönemi vardır. Geçiş dönemlerinden ilki doğumdur ki bu evre, bireyin dünyaya gelmesinden önce başlar. İkinci önemli geçiş dönemi evlenmedir. Evlilik, bireyin bilinçli olarak katıldığı bir geçiş dönemidir. Üçüncü önemli geçiş dönemi ise ölümdür. Ölüm geçiş dönemi bireyin ölümünden önce başlar ve ölümünden sonra da süren âdet ve uygulamaları içerir.

Bilinçli olarak katılım ve sürecin tamamında bireyin canlı olması yönleriyle evlilik dikkat çeken bir geçiş dönemidir. "[T]oplumsal yapının temeli” olan "aile" kurumu bu tören neticesinde kurulduğu için evlenme her toplum için önem arz etmektedir (Örnek, 1977, s. 185). Evlilik, bireyin içine doğduğu aileden ayrılarak yeni bir yuva kurması ve kendi ailesini oluşturması sürecinin bütünüdür. Bu anlamda birey, evlendiği güne kadar edindiği bilgi, beceri ve tecrübeleri kendi 'ev'inde yani yeni hayatında kullanacaktır. Ancak yeni hayat, artık onun sosyal statüsünün de değiştiğini göstermekte, 'bekâr'lıktan 'evli' bir bireye, "bir aileden sorumlu bir birey”e dönüştüğüne işaret etmektedir. Bu anlamda evlilik töreni (evlilik öncesi, evlilik dönemi, evlilik sonrası âdetleri ve uygulamaları) bütünüyle, bireyin bekârlıktan evli birey olması sürecidir. $\mathrm{Bu}$ geçiş dönemi, toplumsal uygulamalara bakıldığında çok aşamalı ve uzun bir süreçtir. $\mathrm{Bu}$ süreçte birey yavaş yavaş evlilik hayatına hazırlanmakta ve adım atacağı yeni yuvasında dengeli ve huzurlu bir hayat sürebilmesi için yeni hayatına alıştırılmaya çalışılmaktadır. Birey evlilik geçiş dönemi uygulamaları başladığında bir 'eşik'tedir, evlilik süreci tamamlandıktan sonra eşik aşılmış ve yeni hayata tam anlamıyla geçilmiştir. ${ }^{1}$

Edebî eserlerde çeşitli motif, metafor ve göndermelerle bazı ifadelere işaret edilir. Metafor, Türkiye sahasında yapılan çalışmalarda önceleri bir söz sanatı olarak görülmüş ve istiare (eğretileme) karşılığında kullanılmıştır. ${ }^{2}$ Ancak Lakoff ve Johnson’ın çalışmaları Batı dünyasındaki 'metafor' kavramının yeniden yorumlanmasını ve değerlendirilmesini sağlamıştır (Yaylagül, 2010, s. 112). Bu yeniden yorumlama sonucunda metaforun önceki "figüratif fonksiyonu kayb[olduğu]" için yerine "kavramsal metafor" terimi kullanılmaya başlanmıştır (Şahan, 2020, s. 73). Kayhan Şahan bunu şu şekilde ifade etmiştir:

1 Nikâh öncesi, bireyin henüz eşiği geçmediği anlamına gelmektedir. Ögel'in alıntısı da bu eşiğin aşılmamış olduğunun kabulüne işaret etmektedir: "Nişanlı kızlar da, kalın paraları tam olarak ödenmemiş ve nikâh gerçekleşmemişse, ocağın ateşinden, pipolarını bile yakamazlardı. (Yani o eve henüz yabancı sayılırlardı)" (Direnkovna, 1927 ve Harva, 1938'den aktaran; Ögel, 2006, II, s. 512). Yine Ögel "Evli kız, baba ocağına, artık yaklaşamıyor" diyerek bu eşiğe işaret etmektedir (Ögel, 2006, II, s. 511). "Evin sahibi ile aynı soydan gelmeyen kişilerin ateşin yandığı ocağın karşısında, yanında oturmasının yasak olmasında ailenin karakteristik özelliği ön plana çıkmaktadır" (Ergun, 2010, s. 277). Bu anlamda yeni aileye dâhil olma, ancak evlilik geçiş dönemi tamamlandığında gerçekleşmektedir.

Benzer bir şekilde, gelinin yeni evine geldiğinde eşiği sağ ayağıyla geçmesi de sadece yeni bir eve ilk adımın atılması değil aynı zamanda yeni hayatına başlaması ve geçiş döneminin aşılması anlamına işaret etmektedir.

2 Türkiye sahasında gerek dil, gerekse edebiyat alanında yapılan çalışmalarda, metafor kavramının anlamlandırılması süreci hakkında ayrıntılı bilgi için bkz.: (Şahan, 2020, s. 23-33; 45-59). 
Metafor figüratif bir unsur değil insan zihninin işleyiş prensiplerinden biridir. İnsan zihnine giden bu yol elbette bize kültür ve medeniyet araştırmalarında da kapı açmıştır. Günlük dilde metafor kullanımı hem kişisel bazda hem de toplumsal bazda verilerin elde edilmesini sağlar. Metinde ya da konuşmada bir kişinin dilsel ifadeleri çözümlenerek zihinde nasıl bir haritalamaya sahip olduğu görülebilir. Bir nesneyi, düşünceyi, duyguyu nasıl ve ne ile kavramsallaştırdı̆̆ı; yazar/konuşucunun bakış açısını, anlayışını gösterir (Şahan, 2017, s. 11-12).

Şahan'ın ifadesinden, metaforların; kişilerin veya toplumların kavram alanları ile kurdukları yapılar olduğu anlaşılmaktadır. Burada bir metaforun kişisel veya toplumsal olabileceğine işaret edilmesi özellikle dikkat çekmektedir. Bir metafor, onu oluşturan ve kullanan kişi veya toplum hakkında bilgi vermektedir.

Lakoff ve Johnson metaforun özünün "bir tür şeyi başka bir tür şeye göre anlamak ve tecrübe etmek” olduğunu söylemiştir (Lakoff ve Johnson 2015, s. 30). "Metaforun esas fonksiyonu bir tür tecrübenin, tecrübenin bir diğer türüne göre kısmî bir kavrayışını sağlamaktır. Bu önceden varolan izole edilmiş benzerlikleri, yeni benzerliklerin yaratılmasını ve daha fazlasını içerebilir" (Lakoff ve Johnson 2015, s. 202). Bu durum, metaforun iki farklı unsur arasında bağlantılar kurulması gerektiğine işaret etmektedir. Bahsedilen bağlantılar "karşılaştırma" ve/veya "benzetme" yollarıyla kurulabilir (Kök, 2016, s. 104). Burada kastedilen benzetme bağlantısı şeklî bir benzerlikten ziyade anlam/kullanım dünyasına dair kullanan kişinin yaklaşım/anlayışı ile bağlantıdır. ${ }^{3} \mathrm{Bu}$ da kelimelerin 'kavram alanları' ile birlikte düşünülerek yorumlanması gerektiğini göstermektedir.

"Metafor, iki kavramın kavramsal alanlarının birbiri üzerine (sonsuz) haritalanmasıdır." (Şahan, 2017, 13). Bu haritalama yapılırken kendi tecrübelerimiz ve karşımızdaki kişinin muhtemel düşünce dünyasına yönelik olarak kavramların bağlantılandırılarak kullanıldığını göz önünde bulundurmalıyız. Başka bir deyişle "[h]aritalamayı karşıdakinin yazıp okumasını bekler ya da biz açıklama yoluna gideriz” (Şahan, 2017, s. 14).

Metaforların zihnimizde oluşması, şekillenmesi ve kullanılması her ne kadar bireysel bir eylem/düşün gibi görünse de bazı metaforların toplumun bütününde aynı şekilde anlaşıldığı ve kullanıldığı; dolayısıyla metaforun toplumun kültürüyle ilgili olduğu görülmektedir. Kolektif şuur ve şuuraltı tesiriyle ve toplumun kültürü tarafından şekillenen metaforlar, gelenek içinde kullanılarak yeni nesle aktarılır. Bu aktarımda en önemli pay 'dil'indir. "Toplumların farklı metaforları olacaktır ve bunlar bir konuya karşı kültürlerin farklı tutumlarını ortaya koyacaktır” (Şahan, 2017, s. 15). Metaforlar 'dil' vasıtasıyla taşındığg için, ne kadar şahsi olsalar da toplumun kültürü ve tutum/düşüncelerini taşır. Dilin, kültürün en önemli taşıyıcısı olması sebebiyle, kültürel yaklaşım farklılıklarının dilsel malzemede daha iyi görülebileceğini düşünebiliriz.

3 Lakoff ve Johnson'ın "anlam, daima birine göre anlamdır. Cümlenin, herhangi bir insandan bağımsız, kendinde anlamı gibi bir şey olamaz.” (Lakoff ve Johnson 2015, s. 237) ifadesinden, kişisel tecrübenin (hem konuşan, hem de dinleyen açısından) anlamı ve anlaşılmayı dolayısıyla metaforun kullanımı ve açıklanmasını etkilediğini anlayabiliriz. 
Lakoff ve Johnson da "bizimkinden çok farklı kavram sistemlerine sahip insanlar, dünyayı bizim anladığımızdan çok farklı bir tarzda anlayabilir" (Lakoff ve Johnson 2015, s. 234) derken farklı kültür dünyalarının, farklı metafor dünyalarını ve kavram alanlarını oluşturmasını sağladığına işaret etmektedir. Başka bir deyişle metaforlar, kültürler içerisinde 'kültürün kendisine has' kavram alanlarını oluştururlar.

Kayhan Şahan, edebî eserlerde yer alan metaforları iki gruba ayırabileceğimizi söylemektedir: a) "Geleneksel-Kültürel metaforlar"; b) "Yeni (orijinal) metaforlar". Şahan bu gruplamayı "metaforun kökensel bağı ve metin üzerine etkisi” yönünü göz önüne alarak yaptığını ifade etmiştir (Şahan, 2017, s. 17). Şahan'ın burada 'kökensel bağ' ifadesinin 'gelenek ve kolektif şuuraltı' ile ilgili olduğunu düşünebiliriz.

Şahan "edebi metinler hariç haritalanan dilsel ifadelerin tüm toplum tarafindan anlaşılabilir olduğu”nu ifade etmiştir (Şahan, 2017, s. 15). Burada Şahan'ın "edebi metin” olarak yazılı edebiyat ürünlerini ve yukarıda "yeni (orijinal) metaforlar" grubunda yer alan metinleri kast ettiği düşünülebilir. Yani bir yazar/şairin kendi dünyasında geliştirdiği ve kurgusal evrenine yerleştirdiği metaforların tüm toplum tarafından anlaşılamayabileceğini söylemiştir. Bu tip metaforların, şahsi özellikler taşıdığı için, açıklanmaya muhtaç metaforlar olduğu düşünülmüş olabilir.

Sözlü edebiyat ürünleri, gelenek dairesi içerisinde üretildiği ve kolektif şuuraltının izlerini/bağlantılarını taşıdığı için toplumun geneli tarafından, açıklanmaya ihtiyaç olmadan anlaşılabilmektedir. "İnsan dil ile birlikte bu metaforları ya da metaforlar ile dili öğren"diği (Şahan, 2017, s. 15) için sözlü edebiyat ürünleri toplumun geneli tarafından anlaşılmaktadır. Bu, ferdileşme/anonimleşmeme durumunda yani sahibinin bilinmesi ve sahibinin şahsi dünyasının izlerini taşıdığına işaret etmektedir. Her ne kadar üretilen ürün, 'ilk söyleyen'in dünyasından izler taşısa da, bu ürün, içinde bulunulan toplumun kültürü tesiriyle söylenmiştir. Yani, var olan 'kavram haritası'nın üzerine birey kendi metafor bağlantısını eklemiştir. Bu yeni metafor, zamanla üreticisinin unutulması (yani ferdilik hususiyetini kaybetmesi) ve anonimleşerek gelenek dairesinde yer alması neticesinde 'şahsi kurgusal bağlantı'larını kaybedip gelenekle bütünleşir ve gelenek ile kültürün muhafaza ettiği 'kavram haritası'na dâhil olur. Bu durumda, anonim ürünlerin içindeki metaforik işaretlerin büyük kısmının toplumun geneli tarafından kullanıldığ1, aktarıldığı ve anlaşıldığ1 düşünülebilir.

Kavram haritalamalarındaki bir diğer önemli unsur da bağlamdır (Lakoff ve Johnson 2015, s. 214-215; Şahan, 2017, s. 14). Fatih Tepebaşılı "imge tarlası (bahçesi)" terimini tanımlarken şu ifadeleri kullanmıştır: "İfadelerin sahip olduğu veya ona atfedilen semantik özelliklerin bütünüdür. Bunların belli başlıları sözlüklerde yer alabilirler. Ama diğerleri bağlamsaldır.”

4 Ferris kültürün aktarımında rol alan her bir kuşağın birbirlerini çok iyi anladıklarını ve nesiller arası iletişimin aksamadan sürdüğünü söylemiştir. Nesiller arası iletişimin aksamadan devam etmesini ise "zaman birleştirici" (“time-binding”) özelliğine bağlamıştır. (Ferris, 1997, s. 87) Ferris bu düşüncesinin devamında halk şarkılarının üstlendiği role dikkat çekmiştir: "Halk şarkıları vasıtasıyla birey hem bilinç, hem de bilinçaltı düzeyde kendi kültürünün kökleriyle teması sürdürebilmektedir.” (Ferris, 1997, s. 87) 
(Tepebaşıl1, 2013, s. 19-20). Metaforlar kullanılırken aynı kelime farklı anlam dünyalarıyla karşımıza çıkabilir. Bu farklı anlamların hangi kavramlar veya imajlarla bağlantılı olduğunu anlamak için bağlamın da bilinmesi gerekmektedir. Çünkü " [i]mge tarlası bize içinden uygun olanı seçip alacağımız imkan alanı sunar”' (Tepebaşılı, 2013, s. 20). Bu 'tarla'dan, kelimenin sözlük anlamlarından biri seçilebileceği gibi, sözlükte yer almayan ama bağlamsal olarak manalandırılan imgelerden biri de seçilebilir. ${ }^{5} \mathrm{Bu}$ durum kelimenin imge zenginliğine bağlıdır. Ama bir yandan da metaforu kullanan ve dinleyen kişilerin anlam haritalarında olmasına bağlıdır. İletişimin tamamlanabilmesi için gönderen tarafından verilen mesajın alıcı ${ }^{6}$ tarafından doğru olarak anlaşılması gerekir. Şu hâlde metafor sadece kullanan/üreten kişiye değil; 'dinleyen'e de bağlıdır. Bu da folklorda "bağlam" olarak adlandırılan kavrama işaret eder. Bu durumu yani dinleyici-konuşan/kullanan kişi ilişkisini tersten okursak; bir metafor dinleyenin anladığ 1 şekilde yorumlanır ama bu anlam kullanıcının veya diğer dinleyenlerin anladığı/düşündüğü şekilde olmayabilir. Burada metnin bireysel geçmiş veya edinimine göre yorumlaması hususiyeti karşımıza çıkar. Ancak geleneksel kaynaklı metaforlar toplumun genelinde aynı şekilde anlaşılabilir diyebiliriz çünkü metaforun kodları toplumun geneli tarafından bilinmektedir. Dolayısıyla, bağlam ile geleneğin sözlü edebiyat ürünlerinin metaforik dünyasını şekillendirmede son derece etkili olduğu anlaşılmaktadır.

Türk Sözlü Edebiyatı'nın birçok ürününde, görülen anlamın haricinde kullanılan kavramların göndergelerine göre metaforik anlamların bulunduğunu düşünebiliriz. ${ }^{7} \mathrm{Bu}$ çalışmada ise türkülerde geçen 'köprü' ifadesinin, 'evlilik geçiş dönemi' metaforik anlam bağlantıları örnekler ile açıklanacaktır. ${ }^{8}$ Çalışmada değerlendirilen türkü metinlerine Türk Halk Müziği Sözlü Eserler Antolojisi (2006) adlı eserin taranması yoluyla ulaşılmıştır. Eserdeki türkü metinlerinin söylenme bağlamı hakkında eserde çoğunlukla bilgi verilmemiştir. Çalışmada türkülerin söylenme bağlamına ulaşılanlar belirtilmiş, bağlamına ulaşılamayan ancak anlam bağlantıları göz önünde bulundurulduğunda metaforik kullanımı taşıdığı düşünülen eserler değerlendirilmiştir.

Türk Anonim Sözlü Edebiyatı'nın en yaygın türlerinden olan türküler, toplumun bilinçaltını yansıtan birçok metaforu içinde barındırmaktadır. Türkülerdeki metaforlardan bazıları mitolojik kökenlere sahipken ${ }^{9}$ bazıları da toplumun kurumları ve bireyin hayatına dair ipuçları taşımaktadır.

5 "Geçerli anlamın hangisi olduğunu ilgili bağlam belirler" (Tepebaşılı, 2013, s. 21).

6 "Gönderen" ve" alıcı" terimleri hakkında ayrıntılı bilgi için bkz.: Kartarı, 2001, s. 18-20.

7 Bkz.: Yaylagül, 2010; Temur, 2018.

8 Fatih Tepebaşılı, metaforun oluşum ve kullanım sürecinde kazandığı anlamın "fiziksel olarak kanıtlanama"dı̆̆ını söyler ve bu kelimelerin "metaforik olarak kavramlaştırıl”dığına işaret eder. Bahsi geçen süreçte "önceden belirlenmiş değişmez ve mutlak belirlenebilen bir yapının tanımlanmasına hizmet etmez” (Tepebaşıl1, 2013, s. 11) diyerek bir metaforun her zaman aynı anlamda kullanılmayabileceğine işaret etmiştir. Burada anlamın netleşmesini sağlayan, yukarıda da belirtildiği gibi, bağlamdır. Bundan dolayı “"köprü’ kelimesinin kullanıldığı her türküde bu metaforik anlam vardır” denilemez. Bazı türkülerde metaforik anlam kullanılmamış, bazı türkülerde ise farklı metaforik anlamlara gönderme yapılmıştır. 
Köprü, Türk Dil Kurumu’nun Güncel Türkçe Sözlük'ünde “Herhangi bir engelle ayrılmış iki yakayı birbirine bağlayan veya trafik akımının, başka bir trafik akımını kesmeden üstten geçmesini sağlayan ahşap, kâgir, beton veya demir yapı" olarak tanımlanmıştır. Aynı sözlükte bu kelimenin mecazen "İki şey arasında bağ veya ilişkiyi sağlayan şey” anlamına geldiği de belirtilmiştir. ${ }^{10}$ Burada iki yaka arasında bağlantıyı sağlaması yönünden ırmak üstüne kurulan köprüler bazı türkülerde hem gerçek anlamıyla hem de metafor olarak kullanılmıştır. Bazı türkülerde ise köprünün sadece gerçek anlamıyla kullanıldığı görülmektedir. Köprünün yıkılması sonucu akarsuya düşen gelinlerin arkasından söylenen yas konulu olay türküleri bunlardan ilk akla gelenlerdendir. Örneğin Sivas yöresine ait olan "Köprüye varınca köprü yıkıldı" (THMSEA2 ${ }^{11}$, s. 565) mısraıyla başlayan türküde köprünün yıkılması sonucu Kızılırmak’a düşen gelin ve gelin kafilesi anlatılmaktadır.

Türkülerde geçen “köprü” her zaman sadece bir "yapı”ya işaret etmemektedir. Bazı türkülerde 'köprü'nün, insan hayatındaki önemli geçiş dönemlerinden olan evlilik sürecine işaret ettiği düşünülebilir. Köprünün iki yakayı bağlaması gibi, evlilik süreci de insanın hayatındaki bekârlık ve evli olma durumu arasında bir geçişi sembolize etmektedir. Köprünün ayaklarından biri bekârlık döneminde yer alırken, diğer ayağı evlilik dönemine basmaktadır. Bu iki dönem arasındaki geçiş dönemi, köprü ile sembolize edilmiştir. Evlilik geçiş dönemi ve törenleri evlilik öncesi, esnası ve sonrası ile birlikte düşünüldüğünde oldukça uzun bir süreci kapsamaktadır. Anadolu'da birçok yerde gençlerin birbirini beğenmesi/birbirleriyle tanışması ve 'kız isteme' ile başlayan bu süreç söz kesme, nişanlanma, çeyiz ve kına merasimleri, düğün töreni ve düğün sonrasına gelin olan kızın baba evini ilk ziyaretini de içine alan oldukça uzun bir zaman dilimine yayılmıştır. Bir köprüden bir iki adımda geçilmediği gibi, evlilik geçiş dönemini tamamlamak uzun sürmektedir.

Türkülerin bağlamlarının bilinmesi elbette bu anlam dünyasının oluşturulmasında önemlidir. Ancak ne yazık ki her türkünün söylenme bağlamı hakkında yeterli bilgi elimizde bulunmayabiliyor. 'Köprü' kelimesinin evlilik geçiş dönemi metaforu olarak yorumlanması hakkında ise Sivas'ta kına gecesinde söylenen şu türkü metni oldukça önemli bir yere sahiptir:

Geline bak geline, geline bak geline

Kına yakmış eline, kına yakmış eline

Gelin kurbanın olam, gelin kurbanın olam

Senin ince beline, senin ince beline/

'Yazık olmuş geline, düşmüşs sarhoş eline'

Diloy diloy diloy diloy, halden bilmez biçare

Diloy diloy diloy diloy, döz anlamaz ne çare

10 https://sozluk.gov.tr/e -Erişim tarihi: 14.05.2021.

11 THMSEA: Türk Halk Müziği Sözlü Eserler Antolojisi adlı eserin kısaltması olarak kullanılmıştır. THMSEA1, eserin birinci cildine, THMSEA2 ise eserin ikinci cildine işaret etmektedir. 
Köprüden geçti gelin

Saç bağın düştü gelin

Eğil bir yol öpeyim

Yüreğim geçti gelin

Nakarat

Köprünün altı diken

Yaktın beni gül iken

Allah da seni yaksın

Üç günlük gelin iken

Nakarat

Köprünün altı yaldız

Nerden geliyon baldız

Sen git de bacin gelsin

Yatamıyom yalnız

Nakarat

Köprüden geçer iken

Köprü salladı beni

İtin köpeğin oğlu

Gafil avladi beni (Karaca, 2016, s. 108-109).

Nesrin Karaca, "Kına Gecesi Törenleri” başlığında yer verdiği bu metnin altında, "gelin türküsü"nde yer alan "köprü” kelimesinin "hem sözlük, hem mecaz anlamıyla insan hayatında bir geçiş olan evlenmeye yönelik” olduğunu söylemiştir (Karaca, 2016, s. 109). Burada, metnin kına gecesinde yani evlilik geçiş döneminin sonlarında ve sürecin neredeyse bitmek üzere olduğu bir bağlamda söylendiği görülmektedir. Özellikle türkünün 2. ve 5. dörtlüklerinin varyantları, aşağıda incelenen türkü metinlerinde karşımıza çıkmaktadır. Dolayısıyla, buradaki metaforik anlamın diğer metinlere de taşındığ düşünülebilir.

Sadi Yaver Ataman tarafından Ordu'nun Ünye ilçesinden derlenen "Köprüyü dolanma" adlı türkü "Gelin ağlatma havası"dır. ${ }^{12}$

Köprüyü dolanma (anam) köprü yıkıktır

Gelin olan gızın (da a canım) bağrı yanıktır ${ }^{13}$

Bağlantı: Eyvah eyvah hem anamdan ayrıldım

Hem babamdan hem silamdan ayrildım (THMSEA2, s. 565).

12 https://www.notaarsivleri.com/NotaMuzik/kopruyu_dolanma_kopru_yikiktir.pdf - Erişim tarihi: 23.03.2021.

13 Bu dize, kaynakta şu şekildedir: "Gelin oğlan gızın (da a canım bağrı yanıktır”. 
Bu türküde yeni gelin olmuş, evlilik süreci tamamlanmış/tamamlanmak üzere olan bir kız konuşmaktadır. Bu kız annesine seslenmekte ve baba ocağından ayrılmanın hüznü dolayısıyla 'bağrının yanık' olduğunu söylemektedir. Türküye "Gelin ağlatma havası” alt başlığı verilmesinden bu metnin düğünlerde, özellikle kına gecelerinde gelinin eline kına yakılırken, gelini ağlatmak için söylenen türkülerden biri olduğu anlaşılmaktadır. ${ }^{14}$ Yukarıda verilen türküyü de göz önünde bulundurarak 'köprü'nün metaforik anlamıyla metni yeniden değerlendirdiğimizde gelin olan kızın artık köprüden geçmiş, evlilik geçiş dönemi tamamlanmış/tamamlanmak üzere olduğu anlaşılmaktadır. Gelin olan kızın annesi ise kızının arkasından gitmeye çalışmaktadır. Ancak kız burada annesine seslenerek artık geçiş sürecinin tamamlandığını, kendisinin evlilik yakasına ayak bastığını ve geçtiği köprünün yıkıldığı, yani artık baba evine dönüşün olmadığını dile getirmektedir.

Erzurum'dan derlenen "Köprünün başlarında” adlı türkü metinde yine köprü imajı karşımıza çıkmaktadır:

\author{
Köprünün başlarında \\ Otursam taşlarında \\ Benim sevdiğim güzel \\ On sekiz yaşlarında
}

Köprünün başındayım

Sevdamın peşindeyim

Kinamayın ahbaplar

Ben murad üstündeyim (THMSEA2, s. 565).

$\mathrm{Bu}$ metinde de konuşan kişi bir erkektir. Erkek on sekiz yaşındaki bir kızı sevmektedir. $\mathrm{Bu}$ gencin "Kınamayın ahbaplar/Ben murad üstündeyim" ifadesinden sevdiği kızla ilgili muradının olduğu, dolayısıyla da ondan ayrılmak gibi bir niyetinin olmadığı anlaşılmaktadır. Metni köprünün evlilik geçiş dönemi manasıyla tekrar okuduğumuzda "köprünün başında" bulanan gencin aslında evlenmek niyetinde olduğu, hatta bu süreci başlatmak üzere olduğu düşünülebilir. Türküdeki genç, kendisini kınayanlara ise "muradına ermek" üzere olduğunu söylemektedir. Özellikle 'murat' kelimesinin, "istek, dilek, amaç, erek, gaye"15 anlamları da göz önüne bulundurulduğunda köprü kelimesinin metaforik anlamını desteklediği görülmektedir. Çünkü bilindiği üzere "murat” kelimesi halk arasında "mutlu olmak", "sevdiğine kavuşmak" anlamlarında kullanılmaktadır. "köprübaşını tutmak" deyiminin anlamı da metnin çağrışım alanına dâhil edilebilir. "köprübaşını tutmak”, deyimi “çok önemli bir yer edinmek” anlamındadır. Türküde konuşan âşı̆̆ın kendi konumunu sağlamlaştırdığı/sağlamlaştırmaya çalıştığı da anlam dünyasının içinde düşünülebilir.

14 Eray Alpyıldız, "kına gecelerinde gelini ağlatmak için söylenen ezgilere 'gelin ağlatma havası"” (Alpyıldız, 2020, s. 270) olarak adlandırıldığını söylemiştir. Genel olarak düğün ritüellerine bakıldığında "[y]eni bir aile kurmanın verdiği heyecan ve heves ile söylenilen eğlendirme işlevli türküler, törenin bir yerinde kesilerek gelinin baba evinden ayrılığının sembolleştirildiği bir içeriğe bürünür”' (Alpyıldız, 2020, s. 270). Alpyıldız'ın 'ayrılığın sembolleştirilmesi' ifadesi, çalışmamızda konu edilen, türkülerdeki metaforik anlam tabakasına işaret etmesi açısından dikkat çekicidir.

15 https://sozluk.gov.tr/ - Erişim tarihi: 08.07.2021. 
Özellikle "köprüden geçmek" ifadesinin kullanıldığı türkülerde bu metaforik anlamın daha belirgin olarak kullanıldığg 1 görülmektedir. TRT arşivinde Kırşehir yöresine ait olarak kaydedilmiş olan "Köprüden geçti gelin” adıyla bilinen türküde köprüden geçen geline seslenen bir delikanlı vardır:

Köprüden geçti gelin

Saç bağı düştü gelin

Diloy loy ey

Haldan bilmez

Diloy loy ey

Söz anlamaz ne fayda

Eğil bir yol öpeyim

Gençliğim geçti gelin

Diloy loy ey

Haldan bilmez

Diloy loy

Söz anlamaz ne fayda

Diloy diloy diloy diloy loy oy

Haldan bilmez diloy oy

Söz anlamaz ne fayda

Köprüden geçemiyom

Az doldur içemiyorum

Diloy loy ey

Haldan bilmez

Diloy loy

Söz anlamaz ne fayda

Sen benden geçtin ama

Ben senden geçemiyom

Diloy loy ey

Haldan bilmez

Diloy loy

Söz anlamaz ne fayda

Diloy diloy diloy diloy loy oy

Haldan bilmez diloy oy

Söz anlamaz ne fayda (THMSEA2, s. 563). 
Bu türkünün, delikanlının başkasıyla evlenen eski sevgilisinin arkasından söylendiği türkünün sözlerinden anlaşılmaktadır. Özellikle türkünün ikinci bendinde "Sen benden geçtin ama/Ben senden geçemiyom" sözlerinden gencin terkedildiği anlaşılmaktadır. Gencin âşık olduğu kız onu terk etmekle kalmamış, başka biriyle de evlenerek yeni bir hayata başlamıştır. Türkünün, Samsun'un Bafra ilçesinde gelinin baba evinden çıkarıldıktan sonra söylendiği görülmektedir. ${ }^{16}$ Yukarıda, Nesrin Karaca tarafından Sivas'ta kına gecelerinde söylenen türkünün 2. dörtlüğü ile benzer bir dörtlük bu türküde yer almaktadır. Bu iki örnekten hareketle türkü metninin evlilik geçiş dönemi uygulamalarının son bölümünde söylendiği düşünülebilir.

'Köprü', evlilik sürecine işaret eden metafor olarak düşünülerek türkü yeniden okunduğunda burada gelinin sadece yeni evine giderken maddi bir köprüden geçmesine değil aynı zamanda bekârlıktan evliliğe geçtiği sürece işaret ettiği anlaşılmaktadır. Türkünün ikinci bendinde yer alan "Köprüden geçemiyom" ve "Ben senden geçemiyom" ifadeleri yeterlilik fiilinin olumsuz hâliyle kurulmuştur. Burada, türküyü söyleyen kişinin köprüyü geçmediği değil, geçemediği yani bu işi yapmaya muktedir olmadığı görülmektedir. Aynı şekilde, türküdeki delikanlının sevdiği kızdan vazgeçmediği değil, vazgeçemediği karşımıza çıkmaktadır. Özellikle terkedilme durumu da göz önünde bulundurulduğunda, türküyü söyleyen gencin aslında, gelin olup giden sevgili ile evlenme isteğinin olduğu ancak bunu gerçekleştiremediği düşünülebilir.

Köprüden geçmek ifadesini takip ettiğimizde başka türkülerde de bu ifadenin olumlu veya olumsuz yönleriyle kullanıldığı görülmektedir.

Yozgat'ın Akdağmadeni ilçesinden derlenen “Dar köprüden geçerken” türküsünün ilk dörtlüğü şu şekildedir:

\section{Dar köprüden geçerken \\ Köprü salladı beni \\ Gidi zalımın kızı \\ İpsiz bağladı beni}

Bağlant1:

Dar yerlerde gezdirmedim ben seni

Kötü söyleyip küstürmedim ben seni (THMSEA1, s. 255).

Metinde konuşan kişi bir erkektir. Türküyü söyleyen erkek “dar köprüden geçerken köprünün sallandığg”"ndan ve “ipsiz bağlandığg”"ndan bahsetmiştir. 'İpsiz bağlanmak' ifadesi gencin sevgilisine gözü kapalı bir şekilde âşık olduğunu göstermektedir. Nakaratla birlikte okunduğunda türküde hitap edilen kızın el üstünde tutulduğuna işaret edilmektedir. Bu sözler nazlanan/küsen birinin gönlünü almak için de söylenmiş olabilir. Bu şekilde düşünüldüğünde köprünün sallanması, sevgilisi/nişanlısı küsmüş olan bir gencin durumun ayrılığa varması

16 https://www.haberturk.com/samsun-haberleri/79180093-bu-kopruden-gecmeyen-gelin-dugun-salonunagitmiyorneset-ertasin-kopruden-gecti-gelin - Erişim Tarihi: 08.07.2021. 
tehlikesine işaret etmesi olarak düşünülebilir. Erkek, kızı ikna etmek için 'ipsiz bağlandığı'nı da söyleyerek ona bağlılığını göstermektedir.

Selanik’ten derlenen “Köprüden geçer iken” türküsünün ilk dörtlüğünde de köprünün geçerken sallandığı söylenmiştir:

\author{
Köprüden geçer iken \\ Köprü salladı beni (Emine'm de) \\ Elin oğlu değil mi \\ Düşman belledi beni (Emine'm de) (THMSEA2, s. 563).
}

Bir kızın ağzından söylenmiş olan türküde köprüden geçerken köprünün sallandığ1 söylendikten sonra, elin oğlu şeklinde işaret ettiği sevgilisi/nişanlısının kendisine düşman gibi davrandığından bahsedilmektedir. Burada köprünün evlilik geçiş sürecine işaret ettiği düşünülürse, türküde konuşan kızın evlilik sürecinde olduğu ancak karşısındaki kişinin düşman gibi kötü davranışlarının kendisini tedirgin ettiğini dile getirdiği anlaşılmaktadır. Özellikle yeni bir hayata başlayacak bir çift için bu tedirginlik evlilik süreci ve gelecekteki mutlulukları açısından oldukça tehlikelidir.

\title{
SONUÇ
}

"Metafor, iki unsur (A ve B) arasındaki ilişkiye (C) dayanır" (Tepebaşı11, 2013, 17). Burada A, "hedef”tir, “imge alıcısı"dır (Tepebaşılı, 2013, s. 18), “soyut ve karmaşıktır” (Tepebaşılı, 2013, s. 35). B, “kaynak”tır, “imge göndericisi”dir (Tepebaşıl1, 2013, s. 18 ), "kaynaklar genellikle somut ve basittir." (Tepebaşıl1, 2013, s. 35) C ise, "semantik özellikler”e işaret eder (Tepebaş1l1, 2013, s. 19).

Yukarıdaki örnekler doğrultusunda baktığımızda 'köprü', 'kaynak'tır ve 'hedef' ise evlenme geçiş dönemidir. Hedef ve kaynak arasındaki anlam bağlantılarını ise şu şekilde gösterebiliriz:

\begin{tabular}{|l|l|}
\hline Köprü & Evlilik geçiş dönemi \\
\hline İki yaka, farklı toprak parçaları. & Bir yakası bekârlık, bir yakası ise evli olma durumu. \\
\hline Köprünün birden geçilememesi / uzun olması. & $\begin{array}{l}\text { Evlilik törenlerinin uzun bir sürece yayılması ve çok } \\
\text { aşamalı olması. }\end{array}$ \\
\hline $\begin{array}{l}\text { Köprü, aşılması gereken bir engelin aşılmasını sağlayan } \\
\text { bir vasıdadır. }\end{array}$ & $\begin{array}{l}\text { Toplumsal açıdan bakıldığında, evlilik, atlanması } \\
\text { beklenen/istenen bir 'eşik'tir. Eşik burada hem baba } \\
\text { evinin eşiğine, hem de yeni bir hayata başlamaya işaret } \\
\text { etmektedir. Toplum, bekâr bireyin evlenmesini ister } \\
\text { çünkü evlilik kurumuna önem verir. }\end{array}$ \\
\hline $\begin{array}{l}\text { Köprünün sağlam ve stabil olması, köprüden geçecek } \\
\text { kişilerin güvenliği açısından önemlidir. }\end{array}$ & $\begin{array}{l}\text { Evliliğe geçiş sürecinin karmaşadan uzak ve huzurlu } \\
\text { bir şekilde atlatılması, yeni bir hayata başlayacak } \\
\text { kişilerin huzuru açısından önemlidir. }\end{array}$ \\
\hline $\begin{array}{l}\text { Köprünün sallanması, üzerinden geçen kişiyi tedirgin } \\
\text { edebilir. Bu tedirginlik durumu, kişinin köprüden } \\
\text { geçmek istememesine sebep olabilir. }\end{array}$ & $\begin{array}{l}\text { Evlilik geçiş döneminde yaşanan olaylar, kişilerin yeni } \\
\text { kuracakları hayata dair tedirginlik yaşamasına sebep } \\
\text { olabilir. }\end{array}$ \\
\hline
\end{tabular}


Kayhan Şahan, “[m]etaforlar; yarattıkları haritalama ile şiir diline yön verdikleri gibi, şiir dilini standart dilden ayıran anlam daireleri yaratırlar. Şairler de eserlerinde metafor aracılığıyla hem toplum hafızasını yansıtırlar hem de orijinal yaratımlarıyla toplum zihnine yeni kavramsallaştırmalar eklerler" (Şahan, 2017, s. 20) diyerek metafor kullanımında bireysel buluşların önemli olduğu kadar toplumsal hafızanın yerine dikkati çekmiştir.

'Köprü’ kelimesi de önce bir icracı tarafından metaforik göndergesiyle kullanılmış, daha sonra toplumun bu anlamlandırmayı beğenmesi ve onaylaması neticesinde yaygınlaşıp kalıplaşmıştır. $\mathrm{Bu}$ anlam zenginleşmesi ile toplumun evlilik hakkındaki yargıları ve 'yükleme'leri edebî metinlerde de hissettirilmiştir. Bu metinlerin içine yerleştirilmiş olan bu mana, anlayanlar için metin içinde konuşanın evlilik hakkındaki bireysel algılayışını daha derinden anlamayı ve hissetmeyi sağlamıştır. Bazı türkülerde bu anlam evliliğe dair olumlu hislere işaret etse de, bazı türkülerde konuşan kişinin kaygısı dinleyenlere üstü kapalı bir mesaj gibi verilmektedir. Özellikle yeni hayatına başlamadan önce yaşadığı tedirginliği ifade edemeyen kişi, bu metaforik kullanım yoluyla dinleyenlere hislerini açmaktadır.

Folklorun işlevleri açısından bakıldığında icracı veya ilk söyleyenin neden bu şekilde metaforik bir kullanımı tercih ettiği hakkında düşünülmelidir. Tepebaşılı metaforların neden ve nasıl ortaya çıktığına dair söylediği görüşler bizim metaforik kullanımı açıklamamıza yardımcı olacaktır: Metaforlar "[d]ili güzelleştirmek, ifadeleri güçlendirmek. [2-] Dolaylı dil kullanarak eleştirilerden veya sansürden kurtulmak" (Tepebaşılı, 2013, s. 15) amaçlarına yönelik olarak da kullanılabilmektedir. Burada kişilerin kendi hislerine dikkat çekmek ve bu hisleri daha güzel bir dille ifade edebilmek için metaforları kullandığı düşünülebilir. Ancak bunun ötesinde, evlilik hakkındaki hislerini kolayca dile getiremeyecek olan gençler için bu yöntem bir kaçış noktası sağlamaktadır. Özellikle evlilik hakkında olumsuz hissiyata sahipse ve bunu ailesine/çevresine söylemekten çekiniyorsa, bu kullanım en azından onun kendisini ifade edebilmesini sağlamaktadır. Şu hâlde, metaforun ortaya çıkışı/kullanımı ile folklorun "[t]oplumsal ve kişisel baskılardan kurtulmak için bir kaçıp kurtulma mekanizması" (Başgöz, 1996, s. 1) olması paydasında buluştukları görülmektedir.

Hakem Değerlendirmesi: Dış bağımsız.

Çıkar Çatışması: Yazar çıkar çatışması bildirmemiştir.

Finansal Destek: Yazar bu çalışma için finansal destek almadığını beyan etmiştir.

Peer-review: Externally peer-reviewed.

Conflict of Interest: The author has no conflict of interest to declare.

Grant Support: The author declared that this study has received no financial support. 


\section{KAYNAKÇA/REFERENCES}

Alpyıldız, E. (2020). Evlenme geleneğine müzik davranışları açısından bakış: Gelin ağlatma-alma-indirme havaları örneği. Karadeniz Sosyal Bilimler Dergisi, 12(22), 267-277.

Başgöz, İ. (1996). Protesto: Folklorun beşinci işlevi (fonksiyonu). Özkul Çobanoğlu-Metin Özarslan (Yayın sorumluları), Prof. Dr. Umay Günay Armağanı içinde (s. 1-4). Ankara: Feryal Matbaacılık.

Dar köprüden geçerken (2006). Türk Halk Müziği Sözlü Eserler Antolojisi. (1. Cilt). Ankara: TRT Müzik Dairesi Yayınları, s. 255.

Direnkovna, N. P. (1927). “Kult Ognya u Altaysev i Teleut”. SMAE. VI. (bkz. Ögel, 2006, s. 592)

Ergun, P. (2010). Türk gelininin mitolojik göçü. Balıkesir Üniversitesi Sosyal Bilimler Enstitüsü Dergisi, 13(14), 275-290.

Ferris, W. R. (1997). Halk şarkıları ve kültür: Charles Seeger ve Alan Lomax. (F. G. Mirzaoğlu, Çev.). Millî Folklor, (34), 87-93.

Harva, U. (1938). Die religiçsen Vorsellungen der altaischen Völker. Helsinki. (bkz. Ögel, 2006, s. 593)

Karaca, N. (2016). Hayatın 'eşik' durumu bağlamında ve Sivas evlenme geleneğinde 'gelin kültürü'. Türklük Bilimi Araştırmaları Dergisi (TÜBAR), (40), 105-136.

Kartarı, A. (2001). Farklllıklarla yaşamak kültürlerarası iletişim (1.bs). Ankara: Ürün Yayınları.

Kök, A. (2016). Pîr-i Türkistan'ın metafor dünyası (1.bs). İstanbul: Kesit Yayınları.

Köprüden geçer iken (2006). Türk Halk Müziği Sözlü Eserler Antolojisi. (2. Cilt). Ankara: TRT Müzik Dairesi Yayınları. s. 563.

Köprüden geçti gelin (2006). Türk Halk Müziği Sözlü Eserler Antolojisi. (2. Cilt). Ankara: TRT Müzik Dairesi Yayınları. s. 563.

Köprünün başlarında (2006). Türk Halk Müziği Sözlü Eserler Antolojisi. (2. Cilt). Ankara: TRT Müzik Dairesi Yayınları. s. 565.

Köprüyü dolanma (2006). Türk Halk Müziği Sözlü Eserler Antolojisi. (2. Cilt). Ankara: TRT Müzik Dairesi Yayınları. s. 565.

Köprüye varınca köprü yıkıldı (2006). Türk Halk Müziği Sözlü Eserler Antolojisi. (2. Cilt). Ankara: TRT Müzik Dairesi Yayınları, s. 565.

Lakoff, G. - Johnson, M. (2015). Metaforlar hayat, anlam ve dil (1.bs). (G. Y. Demir., Çev.). İstanbul: İthaki Yayınları.

Mirzaoğlu-Sıvacı, F. G. (2005). Türkülerde mitolojik unsurlar. Türkbilig, 10, 34-53.

Ögel, B. (2006). Türk mitolojisi (4.bs) (2. Cilt), Ankara: Türk Tarih Kurumu Yayınları.

Örnek, S. V. (1977). Türk halkbilimi (1.bs). Ankara: İş Bankası Kültür Yayınları.

Şahan, K. (2017). Kavram alanlarının bir haritası olarak metaforlar / Kavram haritalarını okuma projesi: Metaforlar. İbrahim Şahin-Deniz Depe (Ed.). Bir Metafor Olarak Yol ve Yolculuk içinde (s. 11-20). İstanbul: Doğu Kütüphanesi.

Şahan, K. (2020). Şiirde derin yapı metafor modern Türk şiiri üzerine bir inceleme (1.bs). Ankara: Ebabil Yayınları.

Temur, N. (2018). Epik anlatılarda bir geçiş metaforu olarak uyku. Millî Folklor, 15(117), 32-40.

Tepebaş11, F. (2013). Metafor yazıları (1.bs). Konya: Çizgi Kitabevi.

Türk Halk Müziği Sözlü Eserler Antolojisi (2006). Ankara: TRT Müzik Dairesi Yayınları.

Yaylagül, Ö. (2010). Divânu Lügâti’t-Türk’te yer alan atasözlerindeki metaforlar. Millî Folklor, 11(85), 112- 121. 
https://www.haberturk.com/samsun-haberleri/79180093-bu-kopruden-gecmeyen-gelin-dugun-salonunagitmiyorneset-ertasin-kopruden-gecti-gelin Erişim Tarihi: 08.07.2021.

https://www.notaarsivleri.com/NotaMuzik/kopruyu_dolanma_kopru_yikiktir.pdf Erişim Tarihi: 23.03.2021. https://sozluk.gov.tr/e -Erişim tarihi: 14.05.2021, 08.07.2021. 